\title{
Assessing Self-Regulation of Learning Dimensions in a Stand-alone MOOC Platform
}

\author{
https://doi.org/10.3991/ijep.v7i2.6511 \\ Daniel F.O. Onah \\ The University of Warwick, Coventry, United Kingdom \\ d.f.o.onah@warwick.ac.uk \\ Jane E. Sinclair \\ The University of Warwick, Coventry, United Kingdom \\ j.e.sinclair@warwick.ac.uk
}

\begin{abstract}
A capacity for self-regulated learning (SRL) has long been recognised as an important factor in successful studies. Although educational researchers have started to investigate the concept of SRL in the context of online education, very little is yet known about SRL in relation to massive open online courses (MOOCs) or of appropriate strategies to foster SRL skills in MOOC learners. Self-regulation is particularly important in a MOOC-based study, which demands effective independent learning, and where widely acknowledged high dropout rates are observed. This study reports an investigation and assessment of the concept of SRL using a novel MOOC platform (eLDa) by providing study options (either via a self-directed learning or instructor-led learning) using a novel learning tool. In view of this, the research presents general description of self-regulated learning and explored the various existing dimensions used to expose the learners SRL skills. Drawing comparison of the online tool, the results and findings of the data were analysed. The study discusses how the various dimensions contributed to the knowledge representation of the self-regulated learning abilities shown by the learners. We present how these SRL dimensions captured using the measuring instrument contributes to our growing understanding of the distinctive features of the individual learner's self-regulated learning. MOOCs success required a high performance of selfregulated learning abilities which at the moment very little has shown these degree of supporting SRL skills. This paper presents preliminary evaluation of a novel e-learning tool known, as ' $\mathrm{LDDa}$ ' developed to implement this investigation of self-regulation of learning. The research applied a modified online self-regulated learning questionnaire (OSLQ) as the instrument to measure the SRL skills. The modified questionnaire known as MOOC OSLQ (MOSLQ) was developed with a 19-item scale questions that exposes the six SRL dimensions used in this study.
\end{abstract}

Keywords-self-regulated learning, self-directed learning, instructor-led learning, learning patterns, learning modes, MOOCs 


\section{Introduction}

Online education systems such as massive open online courses (MOOCs) with an open environment have grown around the globe and have been broadcasted widely. Nonetheless, many participants who registered for these courses are not completing and thus it led to the high dropout rates publicised in papers and the media. The low accomplishment rates of less than $15 \%$ completion rates have been recognised as one of the main difficulties within MOOCs [1]. MOOC participants represent large online learning community with distinct motivational interest. Research shows that one of the causes of the low completion rate in MOOC could be due to the lack of motivation and procrastination within the learners to self-regulate and engage consistently with the course [2]. It has been known that learners who exhibit the ability to self-regulate their learning perform better academically as compared to learners with non or minimal self-regulated learning skills [3,4]. This research described the self-regulated learning ability identified among different learners' modes of study. The two main modes are: self-directed and Instructor-led modes. The study focuses on examining and investigating whether there exists better performance of self-regulated learning strategies among the learners from related study mode. In order to investigate the selfregulated learning dimensions, a novel 'eLDa' tool was developed to deliver a course in 'Python programming, computing concepts and how to teach computing in schools'. This study introduces this novel approach of learning which aims to allow learners to actively study in their own chosen path, and also providing the framework of an instructional direction to support participants in order to set-goals and to gain access to materials suitable for their own needs.

We predict equal and associated higher or lower SRL skills among the participants, because of the fact that most of our learners are highly educated, professionals, graduates and undergraduates in their different and similar levels. However, that is not the case with this study, our investigation reveals some aspects of low self-regulators observed in some dimensions including help-seeking and task strategies. This demonstrates that even learners of higher educational background may not be able to fulfill all the requirements necessary to be (or of been) called a high self-regulator and may need to improve in some of the strategies (or dimensions) lacking. This research is of imperative and impeccable value to the establishment and encouragement of selfregulated learning in MOOCs and also on the evaluation of the learners' cognitive ability in developing these skills.

The paper is organised as follows, firstly a review of background of self-regulated learning. Secondly, we present a discussion of the various research methods applied in the research. Thirdly, we present preliminary results from our findings. Finally, we then present the research discussion and contribution, the conclusion and further direction. 


\section{$2 \quad$ Related review}

\subsection{Background of self-regulated learning}

At one point or the other we have all observed self-regulated learning during our studies and careers. According to Barnard-Brak et al. [4], self-regulated learning refers to volitional behaviours on individual learners part to succeed in their learning. Those behaviours include but not limited to the following: setting up study goals (goal setting), strategising effective way of solving the task given (task strategies), planning an effective managing study time (time management), deciding on location of study to acquire optimum benefit with low distractions (environment structuring), requesting for assistance from peers and tutors in providing help in area of concern (help seeking) and lastly self-reflection on personal studies to evaluate the goals achieved (selfevaluation). SRL allows learners to approach educational tasks with confidence, diligence and in a resourceful manner [5,6]. Zimmerman explains that self-regulated (SR) learners are knowledgeable and aware of when they are confident on a particular fact and when they posses the skills to resolve the task successfully and also they are aware of when they cannot [7]. On the other hand, unlike passive learners, SR students or learners are known to be proactive seeking out the necessary information needed, and then further develop personal steps to master it. These SRL learners always find a way out of any difficult situation (or obstacle) during their studies and learning processes in order to succeed. In a similar way, SR learners view learning acquisition as a systematic and controllable learning process. The learners accept responsibility for their outcomes and attainment $[8,9,10]$. SR learners are known to be self-starters with extraordinary confident, they are highly persistent during their studies. They choose environments that will help them optimize their learning approach $[9,11,12]$. SR learners seek sufficient information and advice on environment they are most likely to concentrate and learn effectively. According to some studies, SR learners self-direct their knowledge acquisition and self-reinforce during performance enactments $[13,14]$.

When defining SRL, it is imperative to distinguish it from self-regulation processes such as self-efficacy and dimensions (or strategies) which were created to optimize the processes, such as intermediate goal setting, task strategies, time management, environment structuring, help-seeking and self-evaluation as adapted for this study [2, 3]. In another definition, SRL is defined as a self-oriented feedback loop $[15,16]$. This loop involves a cyclic process which allows the students to monitor the effectiveness of their learning strategies and react to the feedback in a variety of ways, such as changing their self-perception in order to alter their learning behaviour strategies [6]. Although this involves the learners showing proactive effort and be vigilant in allocating enough time in preparation in order to initiate control and self-regulate their learning [17]. McCombs view was different, as they view learners as being motivated by an excellent 'sense of self-esteem or self-actualisation' [18]. Other theorist such as self-efficacy, achievement success and cognitive equilibrium favours motives of self-regulated learning [7, 19, 20]. Self regulated learners self-initiate personal activities in order to promote self-observation, self-evaluation, reflexivity in learning, 
and improvement which could be seen in practice sessions, specialty training and competitive activities [9]. Bandura described the ability of the learners to set higher learning goals for themselves after they have achieved initial goals, shows that they possess the quality of self-motivation [21], in a similar theory, Csikszentmihalyi adduced that an enjoyable experience encourages people to continue to engage in an activity 'even at a greater expense of doing it' [22].

SRL involves proactive efforts to seek benefits from the learning process. In this case, the learners are not only self-directed in a metacognitive manner, but also are self-motivated by using integrated skills of self-regulations [23]. In summary, selfregulated learning has been categorized into three main features: (a) the learners use of self-regulated learning strategies or dimensions, (b) the learners responsiveness to self-oriented feedback on learning effectiveness, and (c) the learners independent motivational strategies which were used to achieve desired academic outcomes by incorporating responses of learning effectiveness and SRL skills [10].

\section{$3 \quad$ Methodology}

\subsection{Overarching research methodology and processes}

This study uses design science research methodology as the overarching research methods [24]. This is a paradigm centred on the development and evaluation of an artefact to address a precise problem domain. The data processes used a combination of mixed methods of qualitative and quantitative methods. The data collection process in the study was done using questionnaires created with an adopted instrument $[2,3]$. The data was further analysed using statistical analysis after the coding and categorisation of the 19-item questions into six SRL strategies (or dimensions). The conceptual framework and the processes of the research methods are illustrated in Fig. 1.

\subsection{The eLDa tool}

Research has shown that learners with good knowledge on how to self-regulate their studies perform better than those with less ability to do so $[9,25,26]$. It has been observed that the use of self-regulated learning ability is distinctive to the learner. Although many SRL abilities such as goal setting and task strategies are constructed by the learners to suit their needs. The learning mode and direction chosen by the learners are to help them obtain optimum benefit from the online course. A novel platform, known as 'eLDa', was created to explore the approach and analyse the effects of novel features in order to encourage motivation, support and to foster selfregulation of learning. eLDa is implemented in Wordpress content management system (CMS) with plugins to support the novel features which allows the learners to chose their route to follow in the course in order to attain their own learning objectives or follow the directed path led by the instructor in order for the learners to achieve the course goals. The choice of Wordpress as CMS is imperative as it allows us to build a learning platform to support learners' chosen routes and to meet our 
research objectives. This platform supports two basic modes of learning: self-directed and instructor-led in which a recommended prerequisite order of lessons helps to cover the full course curriculum [27]. Fig. 2 presents the interface of the Computing concepts and Python programming course in this study.

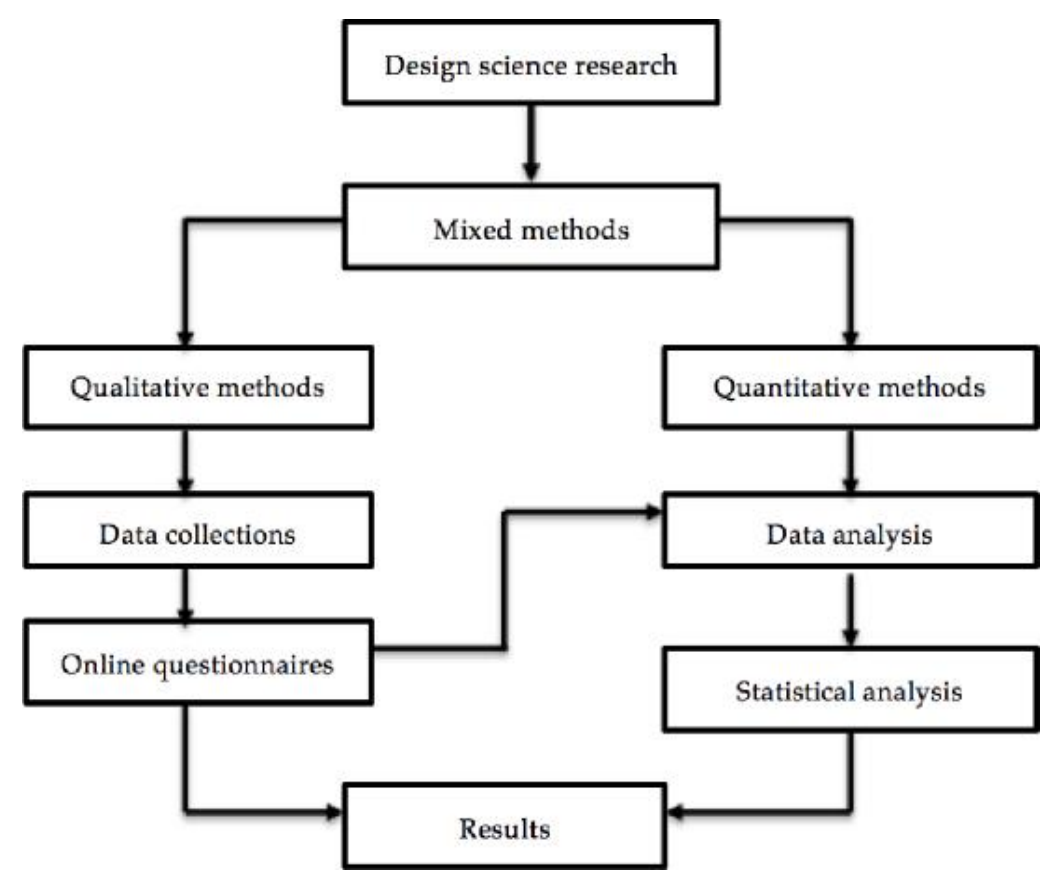

Fig. 1. Conceptual framework of the research methodology

eLDaMOOC - eLearning . Development . Adaptivity

Adapt Learn Platform

My current course - All Courses My Messages My Profile About us Pre-course survey Post course survey

Pre Self-Regulation Strategies Post Self-Regulation Survey

Computer Science: Computing concepts \& Py-

Daniel Onah

thon programming

Log Out

\section{A. In Progress}

Currently completed 2 lessons of 34 in total

Boolean Algebra \& logic gates

Computing concept an introduction

Data structures \& database

eLDa Community

introduction to algorithms

Introduction to software and loops

Programming an introduction

This course will be teaching computing concepts and hands-on Python programming. There will

Programming dictionaries \& morecon

plicated control structures

Fig. 2. Visualisation of the course platform 
Participants: This study consists of a total of 107 registered participants at the beginning of the online course. Of the enrolled learners in this course, $45 \%(n=48)$ have indicated interest by engaging at least once during and after registration. However, only 27 active participants engaged with the course pre-entry survey. Out of this active participants, $59 \%$ identified themselves as male $(n=16)$ while $41 \%$ identified as female $(\mathrm{n}=11)$.

For the self-regulated learning survey questions constructed using the MOSLQ instrument, only a small sample size of 11 learners out of the active 27 participants completed the survey questions used in these research findings.

Data collection processes: The data collection process was carried out using an adopted instrument known as MOOC online self-regulated learning questionnaire (MOSLQ), which was used for measuring self-regulated learning dimensions [2, 3]. A 19-item scale with 5-point Likert-type response format which constituted values ranging from 5-strongly agree to 1-strongly disagree, was applied to collect learners' responses in order for the study to be able to evaluate and answer the research questions. The MOSLQ was conducted using existing dimensions such as: goal settings (GS), task strategies (TS), time management (TM), environment structuring (ES), help seeking (HS), and self-evaluation (SE). Table 1 shows the 19-item MOSLQ instrument questions used for measuring this study.

Table 1. MOSLQ survey question

\begin{tabular}{ll}
\hline GSQ1 & I know what I am going to achieve in this course \\
\hline GSQ2 & I have set aside time to study the course \\
\hline GSQ3 & I have high standards for my work on this course \\
\hline GSQ4 & I have set targets for all I want to achieve in this course \\
\hline GSQ5 & $\begin{array}{l}\text { I do not see my engagement in the course as less important solely because it is an online } \\
\text { course }\end{array}$ \\
\hline GSQ6 & I have written down the goals I plan to achieve by the end of this course \\
\hline TSQ1 & I work strategically to prioritise tasks to help me achieve my learning goals \\
\hline TSQ2 & I prepare for my online study by reading the suggested background learning materials \\
beforehand
\end{tabular}


Procedure: The MOSLQ was administered online to a population sample of $45 \%$ $(n=48)$ participants who have engaged with the course at least once after registration. Within these participants about $56 \%(n=27)$ were active in the course and have responded to the entry survey questions. In this study, $23 \%(n=11)$ responded to the MOSLQ for which most of the SRL dimensions results in this study were based on. However, this study when applied (to a large) in a large-scale population sample could provide significant results. After the data were collected, some of the items were coded and adapted for the research benefits. The questions in the measuring instrument were modified to suit the research objectives. The participants were assured their responses will be anonymous and in confidence. The data were imported from eLDa platform into Microsoft Excel application and then imported to SPSS (v.22.0). The Excel data were converted to comma separated values (csv) file and imported to R-Studio were further analyses was performed in order to compare the results with the SPSS analysis.

Data analysis: Analysis was performed using Statistical analysis. Descriptive evaluation of the data was done using the Statistical Package for the Social Sciences (SPSS) tool. The tool was used to evaluate the learners' responses in order to investigate individual self-regulated learning strategies and also identify the level of selfregulated learning amongst the participants. This analysis helped to reveal areas of SRL dimensions that need improving. Analyses were performed with the average score of the SRL dimensions.

\section{$4 \quad$ Results}

The results indicate better high self-regulated learning skills among learners that chose the path of a self-directed learning as compared to those that followed instructor-led mode of study. Following the responses from the 19-item statements that made the MOOC online self-regulated learning questionnaire (MOSLQ), we present learners associated and different pattern of self-regulated learning skills (as seen in Fig. 3). The discussion and contribution session demonstrates the results interpretation. The individual SRL skills were addressed and levels of each learners SRL skills were identified.

\subsection{Visualisation of learning preferences}

Fig. 4 shows profiles of learners' preferred mode of learning including: interactive learning, collaborative learning, instructor-led learning and self-directed learning respectively. The learning profiles were created by using the frequency of respondents' preferences from the survey questions. The question, which in-formed the knowledge of these preferences, is thus: 'what kind of online course delivery do you prefer?'. The learners can choose more than one option. Fig. 4 presents some interesting results which suggest areas of further exploration. The profile of learners preferring interacting learning reveals over $35 \%$, the second highest preference though very close call was the self-directed learning, which shows approximately $31 \%$. The last 


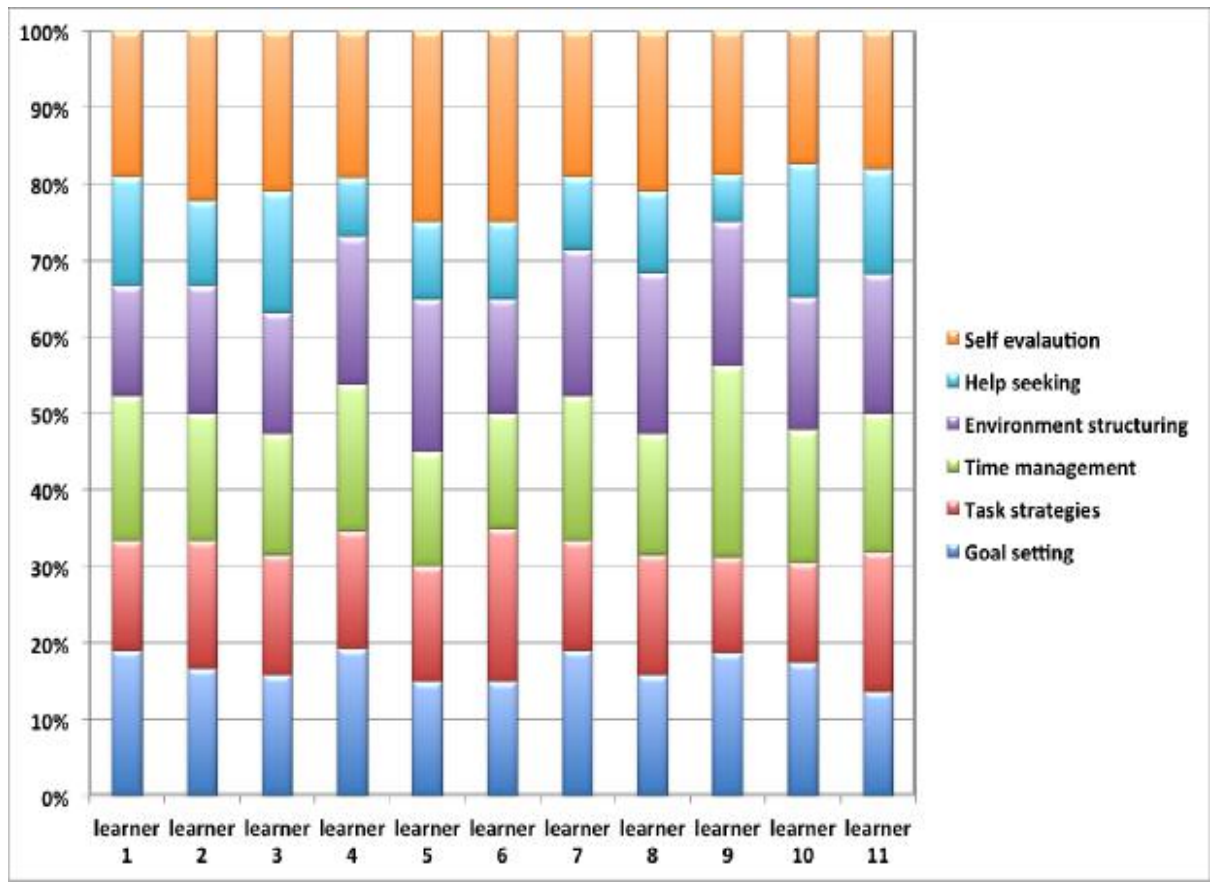

Fig. 3. Visualisation of associated responses from participants

two were instructor-led learning with $19 \%$ and collaborative learning preferences have the least with $15 \%$. Research has shown that collaborative learning is a vital aspect of learning in a MOOC system. These collaborative learning patterns facilitate sharing of knowledge and collaboration between learners of similar learning styles [28]. However this study observed low-level of this learning habit as compared to the others. Interactive learning has been said to be in existence in the early MOOC systems, which mostly have been discussed in xMOOCs primarily centred around the learner's interaction with the course content and essentially "adopting a behaviourist learning approach" and in cMOOCs in the area of social media and interacting with peers in a connectivist learning approach [29]. This was calculated based on the number of responses received. This analysis demonstrates the level of course engagement and preference for which effective participation could be sort. The interactive learning could be in the form of discussion forums, social media, private messages, quizzes, practical exercises and feedback surveys. Most of these features were incorporated in the eLDa platform using compatible Wordpress plugins to support and motivate learning. The learners also appear to self-direct their learning process, which correspond to the result from the SRL results section. 


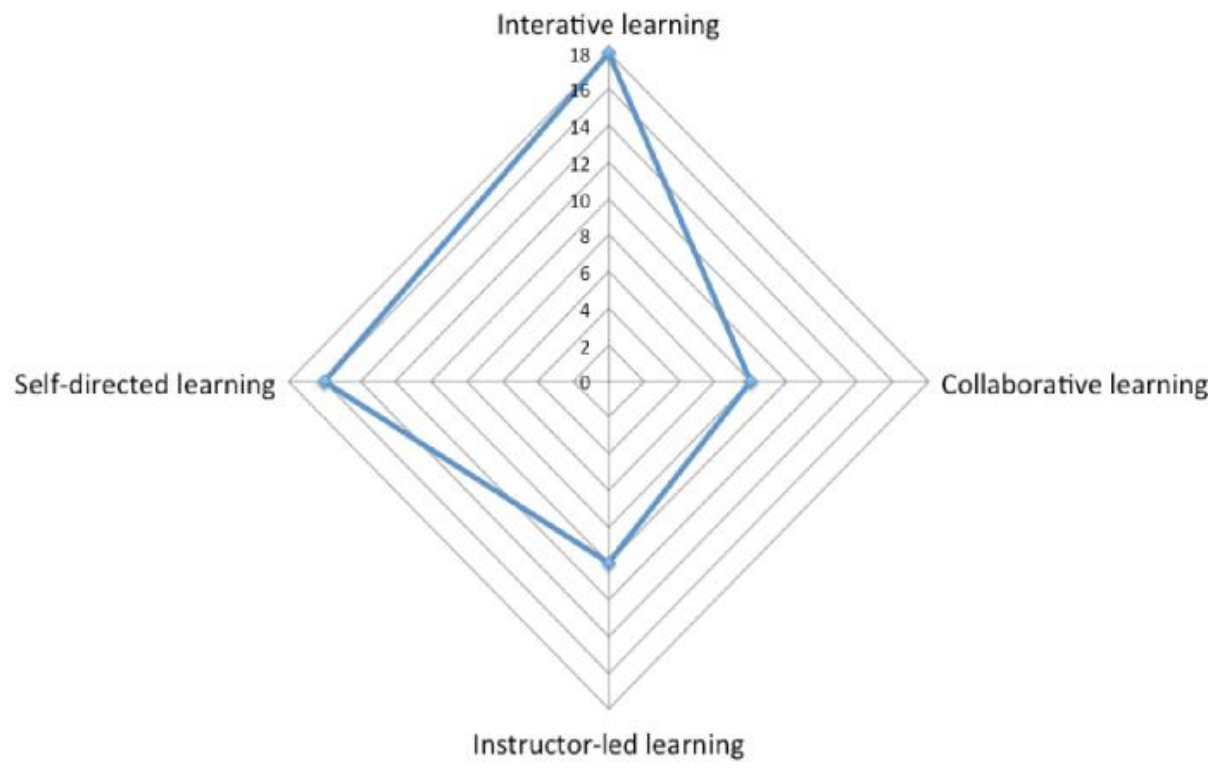

Fig. 4. Learners preferred mode of learning

\subsection{Categorising SRL dimensions}

We are categorising the average SRL dimensions of the learners from the two modes: self-directed and instructor-led modes. During the data collection process using the course entry survey, there are four options: (1) self-directed learning (2) instructor-led (3) Both modes and (4) undecided. In the survey response, three learners preferred the self-directed route of study, two learners preferred the instructor-led route, three learners again preferred both self-directed mode and instructor-led mode of learning and finally two learners again undecided on which route to follow during their choices of learning. In order for us to categorise the learners and to be able to obtain substantial data in the two main modes in this paper, we decided to group the modes into two major modes. We grouped the learners who preferred self-directed and both-self-directed and instructor-led modes of study into 'self-directed' category and learners who preferred instructor-led modes and those who are undecided into 'instructor-led' category. This classification was done in accordance to satisfying the requirement of one of our research questions as follows:

\subsection{Research Questions}

1. What levels of self-regulated learning (SRL) skills are demonstrated within a diverse MOOC learner group and are there particular areas of weakness which MOOCs should seek to improve?

2. To what extent do learners choose to direct their own path as opposed to following a guided course? 


\subsection{Self-directed learning}

The results show that within the various dimensions of goal setting (GS), task strategies (TS), time management (TM), environment structuring (ES), help seeking (HS) and self-evaluation (SE). The level of self-regulators in these categories varies from learner to learner. The study approximate the calculated averages of the categorised dimensions into two decimal digits as seen in Table 2 and Table 3. The reason for this is to be able to identify the level of competency, in order to help us identify high and low self-regulators. In this study we decided to classify learners who score an average below 3.50 to be low self-regulators and learners with an average score of 3.50 and above to be high self-regulators (this is due to our sample size and to help with the interpretation of the results better). For example the average score of the SRL dimensions for 'learner 2' in self-directed learning mode shows high level of selfregulated learning ability in most of the dimensions except one. This indicates that learner 2 is a competent high self-regulator in all the dimensions and need to improve in help seeking ability as shown in Table 2 . The implication of this shows that MOOC ability for a one-size-fits-all approach might not be fully suitable to all the learners using the idea of self-regulated learning habits. These learners choose to direct their learning, depending solely on their own ability and show low ability to interact or seek for help from other learners. Comparing this finding with other related studies show that some learners in a MOOC pattern of learning will prefer to study alone by themselves. Following the observation from the average column of the self-directed Learning (Table 2), the results indicate the earlier point and we can categorise learners 2 and 7 to be high self-regulators as their average scores of the six dimensions were 3.50 and above. The results in this mode of study also revealed learners $1,3,4,5$ and 6 to be low self-regulators. However, the learners in this study show some abilities and improvement in individual SRL dimensions. For example learner 1 scored high SRL skills in SE dimensions with 4.00, likewise learner 3 who also scored a high 4.50 in SE dimension. Learner 4 scored high SRL in TS and SE skills. Assessing the individual dimension basis, 'Learner 5' scored high SRL skills in GS with score of 3.50, TM with 4.00, ES with 4.00 and SE with 4.00. However, this learner overall is classified as a low self-regulators, even with this individual high scores and limitation observed in HS which is 2.00 and TS which was 2.50, on a final note learner 6 also had high TM skills (as seen in the Table 2).

Table 2. Shows high and low self-regulators in the self-directed mode using the average scores

\begin{tabular}{|l|l|l|l|l|l|l|l|}
\hline & \multicolumn{1}{l}{ GS } & \multicolumn{1}{l|}{ TS } & \multicolumn{1}{l|}{ TM } & ES & HS & \multicolumn{1}{l|}{ SE } & Average \\
\hline Learner 1 & 3.33 & 2.75 & 2.50 & 3.00 & 2.00 & 4.00 & $\mathbf{2 . 9 3}$ \\
\hline Learner 2 & 4.67 & 3.75 & 5.00 & 5.00 & 2.00 & 4.50 & $\mathbf{4 . 1 5}$ \\
\hline Learner 3 & 3.00 & 3.25 & 3.00 & 3.67 & 2.00 & 4.50 & $\mathbf{3 . 2 4}$ \\
\hline Learner 4 & 3.33 & 3.50 & 3.00 & 3.33 & 2.00 & 5.00 & $\mathbf{3 . 3 6}$ \\
\hline Learner 5 & 3.50 & 2.50 & 4.00 & 4.00 & 2.00 & 4.00 & $\mathbf{3 . 3 3}$ \\
\hline Learner 6 & 3.00 & 2.25 & 3.50 & 3.33 & 1.00 & 3.00 & $\mathbf{2 . 6 8}$ \\
\hline Learner 7 & 3.67 & 3.00 & 3.50 & 4.00 & 3.50 & 4.00 & $\mathbf{3 . 6 1}$ \\
\hline
\end{tabular}




\subsection{Instructor-led learning}

The results from the instructor-led learning indicated that there are no high selfregulators as all the learners score an average below 3.50 (seen in Table 3). This result indicated that learner $8,9,10$ and 11 are low self-regulators. The full curve is illustrated and represented graphically in Fig. 5. However, the learners performed very high in some individual dimensions, for example learner 8 on GS and TM score 3.50 each which is classified as high SRL dimension skills, in SE score 4.00 which is also classified as a high SRL skills in this study. Learner 9 scored very high SE skills with 4.00. On the other hand learner 10 scored 4.00 on both ES and SE dimensions which is also considered as high SRL skills in these categories. Finally profiling learner 11 shows 3.75 score in TS, 3.50 in both TM and SE and a high 4.00 score in ES. The result reveals that these four learners in this instructor-led mode of study performed very high in self-evaluation skills. Therefore we can argue that they are high selfregulators in the SE category as seen in Fig. 3. However overall these learners who followed the instructor-led route of study are all classified as low self-regulators due to the fact that their average scores were below 3.50 as demonstrated in Table 3.

Table 3. Indicate high and low self-regulators in instructor-led mode using the average scores

\begin{tabular}{|l|l|l|l|l|l|l|l|}
\hline & \multicolumn{1}{l|}{ GS } & \multicolumn{1}{l|}{ TS } & \multicolumn{1}{l|}{ TM } & \multicolumn{1}{l|}{ ES } & \multicolumn{1}{l|}{ HS } & \multicolumn{1}{l|}{ SE } & Average \\
\hline Learner 8 & 3.50 & 2.75 & 3.50 & 3.33 & 3.00 & 4.00 & $\mathbf{3 . 3 5}$ \\
\hline Learner 9 & 2.83 & 2.50 & 3.00 & 2.67 & 3.00 & 4.00 & $\mathbf{3 . 0 0}$ \\
\hline Learner 10 & 3.00 & 2.75 & 3.00 & 4.00 & 2.00 & 4.00 & $\mathbf{3 . 1 3}$ \\
\hline Learner 11 & 3.00 & 3.75 & 3.50 & 4.00 & 3.00 & 3.50 & $\mathbf{3 . 4 6}$ \\
\hline
\end{tabular}

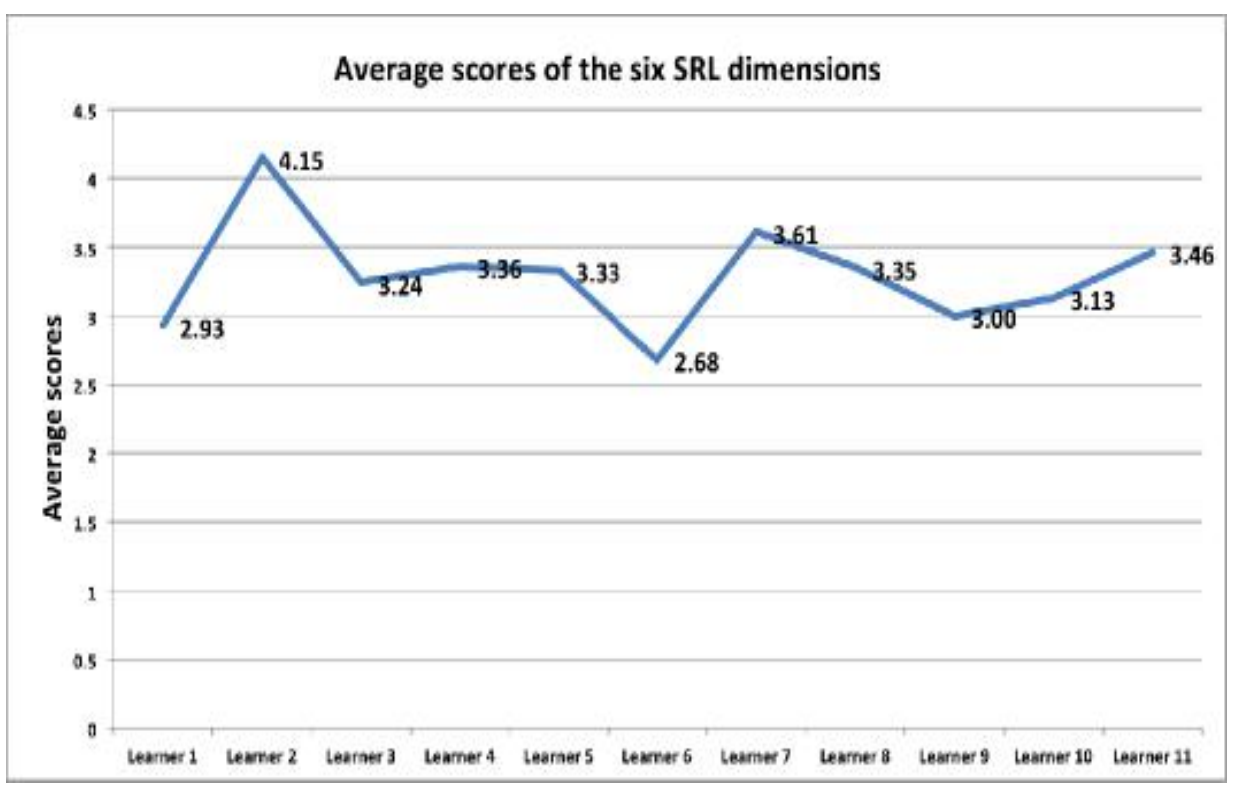

Fig. 5. Overall average score of learners from the six dimensions 
Fig. 6 demonstrates the six SRL dimensions used in this study, the various modes and average scores obtained from each.

Fig. 7 illustrates the direction of the responses received from the learners. The analysis shows no uniform direction and this correlate with our initial discussion about the unique identity brought into the platform by the individual learners in this study which showcase their individuality and also helped them taking control of their studies. The results show discrepancy in the 19-item that made the MOSLQ in order to obtain the learners' SRL skills.

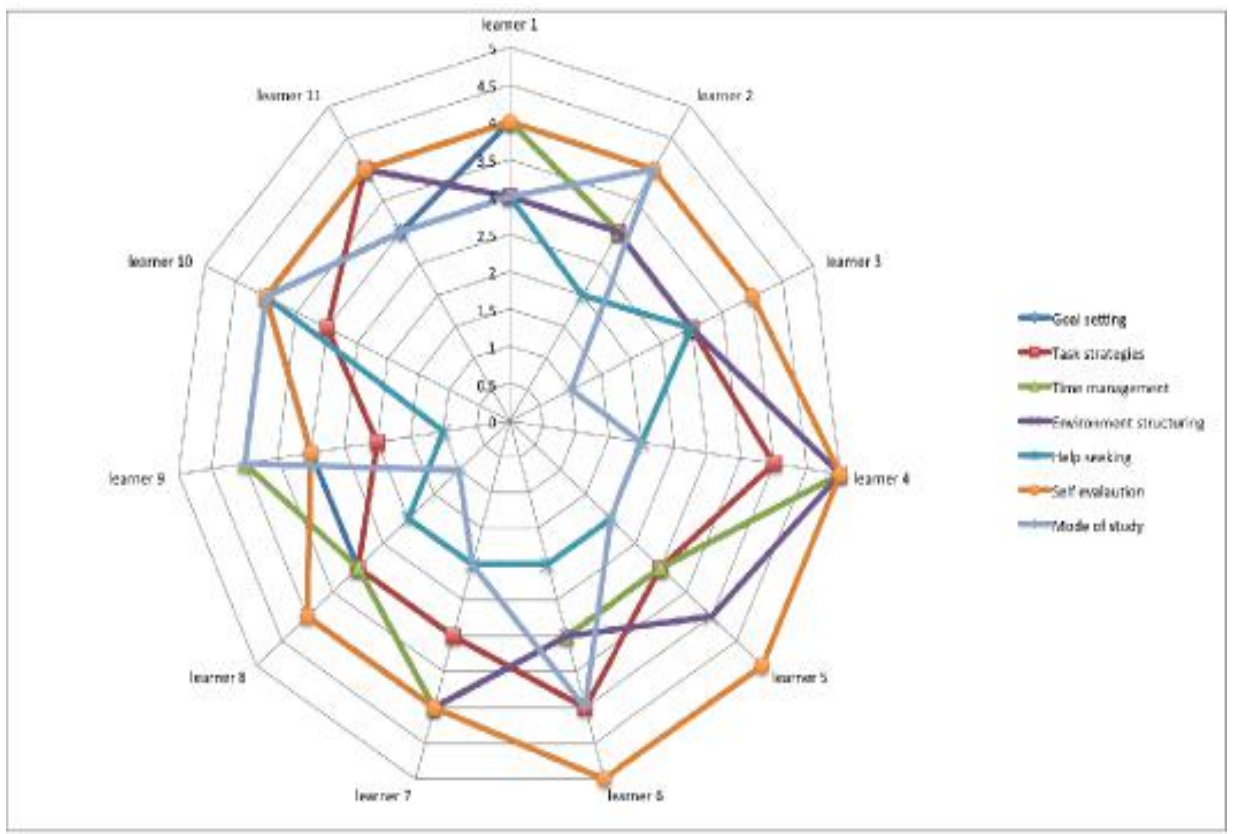

Fig. 6. Learners average SRL dimension Levels and modes of study

SRL-Subscale

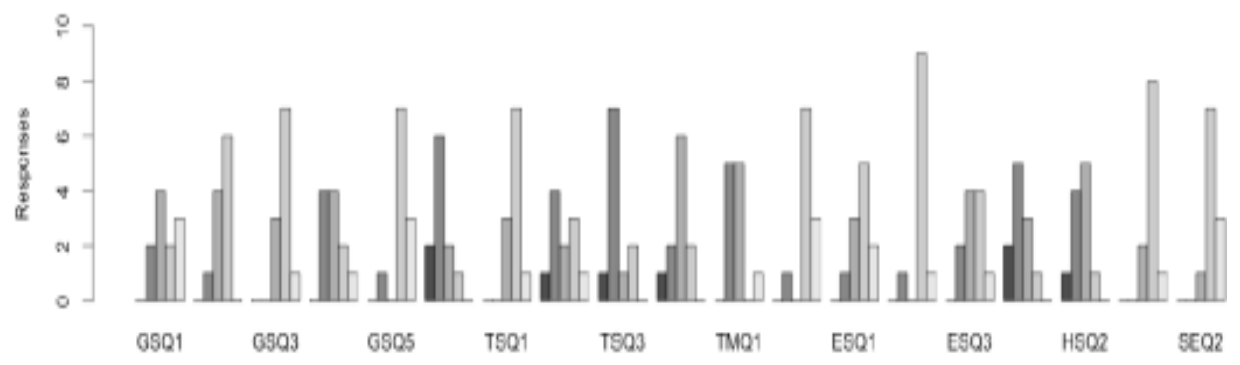

Fig. 7. Responses from the MOSLQ based on the dimensional categories 


\section{Discussion}

Koohang and Paliszkiewicz argued that e-learning courses promote autonomous active learning activities constructed by the learners to enhance their knowledge [30]. This study investigated learners taking the initiative to control their learning and also how the novel platform tool has supported the learners in making informed choices towards directing their learning paths. The tool was able to foster the SRL skills by way of making effective use of features to support the modes of learning. Selfdirected opportunities were offered to learners as well as guided opportunities which were led by the instructor. The main purpose of the instructor-led approach is to introduce lesson prerequisites that will lead the learners to specific (navigation) link containing resources which are associated to their current lesson of study. Although the tool allows flexibility of learning paths, learners are not forced to comply with the prerequisites. They can at any time switch mode of study for which they felt is suitable to the course content they were engaging with at that moment. The learners themselves decide the two main routes of study and they are free to change from one route to another with the support of the features introduced in the eLDa tool. Some studies show that appreciating new features in learning tools could be seen from the perspectives of different learners, as not all learners welcome changes in their routine elearning environment irrespective of the benefits $[31,32]$.

\subsection{Interpretation of results}

Fig. 3 shows the learners ability of self-regulated learning. The study tried to identify the similarities and differences within the various dimensions as indicated by the learners. The following strategies expose the closely related responses as observed from the learners and how these were identified from the chosen categories which form the six dimensions in this study. We present interpretation of the six SRL dimensions in relation to the individual responses as follows:

Goal setting (GS): Goal setting is the process whereby the learners set specific task goals and planned towards achieving them. In our study we observed that learners $1,4,7,9$ and 10 are closely related in terms of their goal setting abilities with higher GS skills while the other group of learners 2, 3, 5, 6, 8 and 11 are closely related in their own respect with lower GS skills. However, both learners categories are different in their responses. The results shows that the first group are more better in their goal setting abilities as compare to the second group as seen in Fig. 3.

Task strategies (TS): Task strategies, as a vital aspect of SRL is the ability of the learners to plan and strategise how to achieve their set goals. The study shows that learners 2 and 8 are closely related in their task strategy ability. Learners $1,3,4,57$, 9 , and 10 are similar in their task strategies with slightly high TS skills, while learners 6 and 11 are associated in their task strategies and show higher TS abilities as compare with others (as seen in Fig. 3). These results show how different learners individually planned towards executing a task. Therefore if given a task, this indicates that similar results will be observed at the end of the task and learners would be able to achieve their set goals in a similar way. 
Time management (TM): Time management is another significant dimension which involves the ability or the skills of time management during study. Our research indicates that learner 9 has the highest time management ability amongst all the learners. While learners $1,4,7$ and 11 are closely associated with slightly higher TM skills and finally learners 2, 3, 5, 6, 8, 10 also had closely related patterns in a low TM skills (as seen in Fig. 3). Time management has been known to be an important factor for online learning, because it helps learners to progress faster in their learning. Therefore in order for any learner to be able to keep up with the pace of the learning, effective time management skills must be develop as the courses are delivered either weekly or fortnightly.

Environment structuring (ES): Environment structuring is an imperative dimension in learning especially in an online or virtual environment. This is the ability of the learners to decide a suitable location for their studies in order to avoid distractions. Most learners in this study and similar studies conducted in the past said the preferred a very quiet environment either online or during an orthodox learning. Our results indicate similar learning patterns within two groups of associated learning style. Our investigation revealed learners 1, 3, and 6 showing related low ES skills while learners $2,4,5,7,8,9,10$, and 11 all show associated learning habits with higher ES skills in the category (as seen in Fig. 3).

Help seeking (HS): Help seeking is the ability of the learners to request for help in areas they have concern while studying online, either in forums or private messages to tutor. Nowadays, one of the most discussed components in MOOC today is the ability to collaborate and interact while learning which are all aspects of discussion forum. Our study shows that most of the learners preferred interactive, independent and self-directed learning typically on their own time and looking up solutions by themselves and at their own pace by researching the web. This aspect of individual self-study style has led to the low help seeking skills as reflected in our study. The result shows low help seeking skills in all the learners, however slightly improve HS skills in learners 1, 3, 10 and 11 (as seen in Fig. 3). In this dimension the scores are different in most of the cases.

Self-evaluation (SE): Self-evaluation is the process of the learner reflecting on their studies in order to understand areas they have achieved their set goals and where they have not that need revising for the future. Our results as shown in Fig. 3 illustrates a greater improvement in this area. This indicated learner 5 and 6 have the highest level of self-evaluated skills in the category. Learners 2, 3, 8 and 9 have similar levels and slightly high SE skills. Finally, learners 1, 4, 7, 10 and 11 are closely related in their self-evaluation, which reveals lower SE skills (as seen in Fig. 3). Personal reflection is of paramount as this enables the learners to understand the areas the need to put in more effort in order to improve in their SRL skills.

The main objective of this study is to understand the SRL strategies in self-directed learning routes and the instructor-led routes. This study also revealed that results were emerging from learners who have decided to switch between both modes. Thus, they are refer to 'learners that preferred both modes' of learning. These new findings will be further explored in the future. 


\section{Conclusion and Future Work}

Although the results presented here are from a small population sample, they indicate SRL dimensions from the two main modes of learning in this study: self-directed modes and instructor-led modes. At the beginning of the course, the learners are given the options of two routes (self-directed and instructor-led) to follow in order to engage effectively with the course. When learners opted for the self-directed routes, they study the resources as they preferred and have the autonomy to move from one lesson content to another without following the prerequisites suggested [33]. But if the learners opted for the instructor-led routes, they are guided in an instructional manner with support from the lesson prerequisites. The lesson prerequisites in this case motivate the learners to build personal and decisive SRL skills while been led to study in a linear way. Our results indicate two distinct representation of the individual profile of self-regulated learning from the analysed sample: high self-regulators and low selfregulators. The results revealed that the competent self-regulators as observed mostly within the self-directed learning, show high level of self-regulated strategies in their responses with few strategies to improve. But for the low self-regulators, these learners need to improve in their self-regulated learning strategies, as most of their responses fell into the negative scale. The results also indicated the individuality of the SRL dimensions observed from the learners, which reveals the different paths that most of the learners wish to follow in their study.

In summary, we define success as not the level of participants who completed the course, but the learners meeting their expectations. A study has shown that some issues of low completion rates in MOOC might not be because the learners are not motivated to participate, but as some of the learners are engaging with the course at their own pace [34]. In this new innovative learning platform (known as 'eLDa'), completion rate was measured in relation to the learners achieving their learning goals. Further investigation of these results will be conducted in order to explore new investigation with a blended module ran within the eLDa platform tool.

\section{$7 \quad$ Acknowledgment}

The first author wishes to acknowledge Mr Adakole. S. Onah's financial support in his research, and family members and friends for their moral support.

\section{$8 \quad$ References}

[1] Jordan, K. (2013). Mooc Completion Rates: The Data. Availabe at: http://www. katyjordan. com/MOOCproject. html.[Accessed: 27/08/2014].

[2] Barnard, L., Lan, W. Y., To, Y. M., Paton, V. O., and Lai, S.-L. (2009). Measuring Selfregulation in Online and Blended Learning Environments. The Internet and Higher Education, 12(1):1-6. https://doi.org/10.1016/j.iheduc.2008.10.005

[3] Barnard, L., Paton, V., and Lan, W. (2008). Online Self-regulatory Learning Behaviors as a Mediator in the Relationship between Online Course Perceptions with Achievement. The 
International Review of Research in Open and Distributed Learning, 9(2). https://doi.org/10.19173/irrodl.v9i2.516

[4] Barnard-Brak, L., Paton, V. O., and Lan, W. Y. (2010). Profiles in Self-regulated Learning in the Online Learning Environment. The International Review of Research in Open and Distributed Learning, 11(1):61-80. https://doi.org/10.19173/irrodl.v11i1.769

[5] Fuchs, L. S., Fuchs, D., Prentice, K., Burch, M., Hamlett, C. L., Owen, R., and Schroeter, K. (2003). Enhancing Third-grade Student'Mathematical Prob-lem Solving with Selfregulated Learning Strategies. Journal of educational psychology, 95(2):306. https://doi.org/10.1037/0022-0663.95.2.306

[6] Puustinen, M. and Pulkkinen, L. (2001). Models of Self-regulated Learning: A Review. Scandinavian Journal of Educational Research, 45(3):269-286. https://doi.org/10.1080/ 00313830120074206

[7] Zimmerman, B. J. (1990). Self-regulated Learning and Academic Achievement: An Overview. Educational psychologist, 25(1):3-17. https://doi.org/10.1207/s15326985ep2501 2

[8] Borkowski, J. G., Carr, M., Rellinger, E., Pressley, M., et al. (1990). Self-regulated Cognition: Interdependence of Metacognition, Attributions, and Self-esteem. Dimensions of thinking and cognitive instruction, 1:53-92.

[9] Zimmerman, B. J. and Pons, M. M. (1986). Development of a Structured Interview for Assessing Student Use of Self-regulated Learning Strategies. American educational research journal, 23(4):614-628.

[10] Zimmerman, B. J. and Martinez-Pons, M. (1990). Student Differences in Self-regulated Learning: Relating Grade, Sex, and Giftedness to Self-efficacy and Strategy use. Journal of educational Psychology, 82(1):51. https://doi.org/10.1037/0022-0663.82.1.51

[11] Henderson, R. W. (1986). Self-regulated Learning: Implications for the Design of Instructional Media. Contemporary Educational Psychology, 11(4):405-427. https://doi.org/10.1016/036 $1-476$ X(86)90032-9

[12] Wang, M. C. and Peverly, S. T. (1986). The Self-instructive Process in Classroom Learning Contexts. Contemporary Educational Psychology, 11(4):370- 404. https://doi.org/10.1016/0361-476X(86)90031-7

[13] Diaz, R. M., Neal, C. J., and Amaya-Williams, M. (1990). The Social Origins of Selfregulation. Vygotsky and education: Instructional implications and applications of sociohistorical psychology, pages 127-154. https://doi.org/10.1017/cbo9781139173674.007

[14] Rohrkemper, M. M. (1989). Self-regulated Learning and Academic Achievement: A vygotskian view. In Self-regulated learning and academic achievement, pages 143-167. Springer. https://doi.org/10.1007/978-1-4612-3618-4 6

[15] Carver, C. S. and Scheier, M. F. (2012). Attention and Self-regulation: A Control-Theory Approach to Human Behavior. Springer Science \& Business Media.

[16] Zimmerman, B. J. (1989). A Social Cognitive View of Self-regulated Academic Learning. Journal of educational psychology, 81(3):329. https://doi.org/10.1007/978-1-4612-3618-4

[17] Zimmerman, B. J. (1989). Models of Self-regulated Learning and Academic Achievement. In Self-regulated learning and academic achievement, pages 1- 25. Springer. https://doi.org/10.1007/978-1-4612-3618-4 1

[18] McCombs, B. L. (1989). Self-regulated Learning and Academic Achievement: A Phenomenological View. In Self-regulated learning and academic achievement, pages 51-82. Springer. https://doi.org/10.1007/978-1-4612-3618-4 3

[19] Schunk, D. H. (1984). Self-efficacy Perspective on Achievement Behavior. Educational Psychologist, 19(1):48-58. https://doi.org/10.1080/00461528409529281 
[20] Schunk, D. H. (1989). Social Cognitive Theory and Self-regulated Learning. In Selfregulated learning and academic achievement, pages 83-110. Springer. https://doi.org/10.1007/978-1-4612-3618-4 4

[21] Bandura, A. (1989). Human Agency in Social Cognitive Theory. American psychologist, 44(9):1175. https://doi.org/10.1037/0003-066X.44.9.1175

[22] Csikszentmihalyi, M. (2016). The Pursuit of Happiness. Bringing the Science of Happiness to Life. Available at: http://www.pursuit-of-happiness.org/history-of-happiness/mihalycsikszentmihalyi/ [Accessed : 13/03/2017].

[23] McCombs, B. L. and Marzano, R. J. (1990). Putting the Self in Self-regulated Learning: The Self as Agent in Integrating will and Skill. Educational psychologist, 25(1):51-69.

[24] Von Alan, R. H., March, S. T., Park, J., and Ram, S. (2004). Design Science in Information Systems Research. MIS quarterly, 28(1):75-105.

[25] Cunningham, C. A. and Billingsley, M. (2002). Curriculum Webs: A Practical Guide to Weaving the Web into Teaching and Learning. Allyn \& Bacon, Inc.

[26] Zimmerman, B. J. (2002). Becoming a Self-regulated Learner: An Overview. Theory into practice, 41(2):64-70. https://doi.org/10.1207/s15430421tip4102 2

[27] Onah, D. F. O. and Sinclair, J. E. (2015). Measuring Self-regulated Learning in a Novel eLearning Platform: eLDa. In Proceedings of the 15th Koli Calling Conference on Computing Education Research, pages 167-168. ACM. https://doi.org/10.1145/2828959.2828986

[28] Onah, D. F. O. and Sinclair, J. (2015). Collaborative Filtering Recommendation System: A Framework in Massive Open Online Courses. INTED2015 Proceedings, pages 1249-1257.

[29] Conole, G. G. (2015). Moocs as Disruptive Technologies: Strategies for Enhancing the Learner Experience and Quality of MOOCs. Revista de Educación a Distancia, (39).

[30] Koohang, A. and Paliszkiewicz, J. (2013). Knowledge Construction in E-learning: An Empirical Validation of an Active Learning Model. Journal of Computer Information Systems, 53(3):109-114. https://doi.org/10.1080/08874417.2013.11645637

[31] Mello, L. V. (2016). Fostering Postgraduate Student Engagement: Online Resources Supporting Self-directed Learning in a Diverse Cohort. Research in Learning Technology, 24. https://doi.org/10.3402/rlt.v24.29366

[32] Entwistle, N. J. and Peterson, E. R. (2004). Conceptions of Learning and Knowledge in Higher Education: Relationships with Study Behaviour and Influences of Learning Environments. International Journal of Educational Research, 41(6):407-428. https://doi.org/10.1016/j.ijer.2005.08.009

[33] McManus, T. F. (2000). Individualizing Instruction in a Web-based Hypermedia Learning Environment: Nonlinearity, Advance Organizers, and Self-regulated Learners. Journal of Interactive Learning Research, 11(2):219.

[34] Onah, D. F. O., Sinclair, J., and Boyatt, R. (2014). Dropout Rates of Massive Open Online Courses: Behavioural Patterns. EDULEARN14 Proceedings, pages 5825-5834.

\section{Authors}

Daniel F.O. Onah is a Doctoral Researcher with the department of Computer Science, The University of Warwick, Coventry, CV4 7AL, United Kingdom (e-mail: d.f.o.onah@warwick.ac.uk). He received his MSc (Eng.) degree in Computer Systems Engineering with specialisation in Software Systems from University of East London, United Kingdom and he is currently a Teaching Assistant in the department of Com- 
puter Science at Warwick University. He is an associate fellow of the UK higher education academy.

Jane E. Sinclair is an Associate Professor with the department of Computer Science, The University of Warwick, Coventry, CV4 7AL, United Kingdom (e-mail: j.e.sinclair@warwick.ac.uk). She received her PhD degree from the Open University, United Kingdom.

Article submitted 11 December 2016. Published as resubmitted by the authors 23 January 2017. 